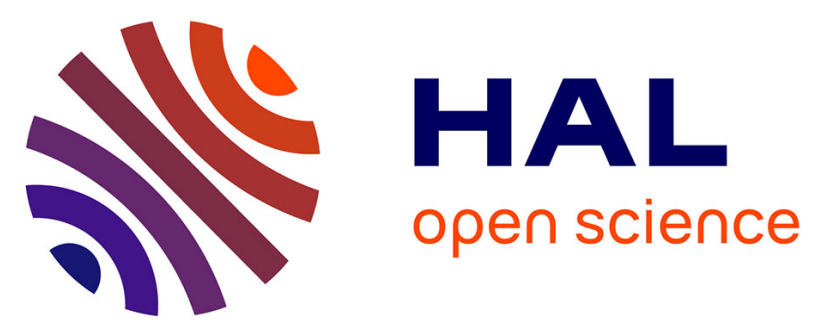

\title{
Fatigue life assessment in notched injection-molded specimens of a shortglass fiber reinforced Polyamide 6 with different injection gate locations
}

Sylvie Castagnet, Carole Nadot-Martin, Nathan Fouchier, Edoardo Conrado, Andrea Bernasconi

\section{To cite this version:}

Sylvie Castagnet, Carole Nadot-Martin, Nathan Fouchier, Edoardo Conrado, Andrea Bernasconi. Fatigue life assessment in notched injection-molded specimens of a shortglass fiber reinforced Polyamide 6 with different injection gate locations. International Journal of Fatigue, 2021, 143, pp.105968. 10.1016/j.ijfatigue.2020.105968 . hal-03022881

\section{HAL Id: hal-03022881 https://hal.science/hal-03022881}

Submitted on 25 Nov 2020

HAL is a multi-disciplinary open access archive for the deposit and dissemination of scientific research documents, whether they are published or not. The documents may come from teaching and research institutions in France or abroad, or from public or private research centers.
L'archive ouverte pluridisciplinaire HAL, est destinée au dépôt et à la diffusion de documents scientifiques de niveau recherche, publiés ou non, émanant des établissements d'enseignement et de recherche français ou étrangers, des laboratoires publics ou privés. 


\title{
Fatigue life assessment in notched injection-molded specimens of a short- glass fiber reinforced Polyamide 6 with different injection gate locations
}

\author{
Sylvie Castagnet ${ }^{\mathrm{a}^{*}}$, Carole Nadot-Martin ${ }^{\mathrm{a}}$, Nathan Fouchier ${ }^{\mathrm{a}}$, Edoardo Conrado ${ }^{\mathrm{b}}$, Andrea \\ Bernasconi $^{\mathrm{b}}$ \\ ${ }^{a}$ Institut Pprime (UPR 3346 CNRS - ENSMA - Université de Poitiers), Département Physique et \\ Mécanique des Matériaux, Poitiers, France \\ ${ }^{b}$ Politecnico di Milano, Dipartimento di Meccanica, Milano, Italy
}

\begin{abstract}
Based on a previously published Through Process Modeling (TPM) for multiaxial fatigue life assessment of injection-molded components, this work aimed to capture the difference of fiber orientation distribution ahead of notch tips in flat notched samples of PA6GF30 tested in tension at ambient temperature. The fiber orientation originated from different locations of the injection gate for an unchanged macroscopic geometry. Good lifetime estimations were obtained in Side- (resp. Top-) injected samples, regardless the choice of the sample type from which the fatigue criterion was identified. The experimentally observed differences of crack initiation zones were correlated to numerical simulations.
\end{abstract}

Keywords: PA6GF30; notch; injection-molding; Through Process Modelling; crack initiation area

\section{Introduction}

Short-Fiber Reinforced Polymers (SFRP) have been widely investigated, for their interesting compromise between mechanical strength and weight as well as their good injection-molding processability. This latter ability is particularly interesting for large series of automotive parts, mainly based on polyamide matrix. To avoid in-service failures, fatigue characterization and relevant fatigue criteria are needed.

On one hand, fatigue lifetime is known to depend on fiber orientation. This effect was widely evidenced in flat dogbone samples machined out of injected plates, in which the core-skin microstructure allows to define a major fiber orientation. Along with the better understanding of deformation and damage micromechanisms in uniaxially stretched samples in tension and fatigue [1-8], many efforts have been paid to improve lifetime estimation from criteria-based approaches [9-16].

On the other hand, composites fatigue lifetime is known to depend on stress concentrations too. This topic has been more investigated in laminate composites but not that much in SFRP. A few studies addressed the effect of holes or notches on the monotonic response and fatigue lifetime [17-22]. Zhou and Mallick [19] showed that holes introduced into flat PA66GF33 samples reduced their fatigue strength under uniaxial loading. Within the range of hole radii (from $1.58 \mathrm{~mm}$ up to $6.35 \mathrm{~mm}$ ), the hole size was of minor influence. An important point in this case was that holes were drilled in samples previously cut into injection-molded plates, so that the local fiber orientation was unchanged.

De Monte et al [20] and Schaaf et al [22] respectively tested PA66GF35 and PBTGF30 samples with several hole radii or notches (curvature radius between 0.2 and $5 \mathrm{~mm}$ ), but the effect of conjugated disordered fiber orientation was not addressed. Among other loading

* sylvie.castagnet@ensma.fr; +33 549498226 
parameters, Sonsino and Moosbrugger [9] addressed the influence of notches in injectionmolded flat PA66GF35 samples with mild and sharp notches (notch radii ranging from 0.2 up to $5 \mathrm{~mm}$ ). At room temperature, they confirmed that increasing the stress concentration factor decreased the fatigue lifetime for the same macroscopic nominal stress amplitude. While a large majority of works only concerned samples, these authors interestingly proposed a methodology for fatigue lifetime estimation in the fuel rail of an engine compartment, which exhibited fatigue failure in sharp notches area. The transposition from the sample to the component, based on the maximum local principal stress in the critical zone, was made possible because the fiber direction in the notches of the specimen was the same as in the critical area. It is not necessarily the case in all components. Quagliato et al. [23] very recently investigated the notch effect on fatigue lifetime in short carbon fiber reinforced Polyamide 6. Interestingly, the proposed approach integrated the local fiber length and orientation (predicted by the MoldFlow ${ }^{\circledR}$ software) into the computation of the mechanical properties at any point of the sample or part. In terms of fiber orientation, the notched samples used to identify the modelling exhibited a less pronounced skin-core effect than usually reported in short-glass fiber polymers. Since notches were machined in samples, the fiber orientation was rather similar for both notches and was not very variable ahead of notch tips.

In many industrial components, the complex geometry (ribs, holes) may enhance both stress concentrations and high disorientation of fibers (i.e. low degree of alignment of fibers with one another) in the same areas, due to the complex flow of the melt during injection-molding. The relative influence of these two effects is not clear. The above cited works did not evaluate the local orientation of fibers around singularities. One of the few attempts was the work by Serrano et al. [24] in structure samples with different injection gate locations. The fatigue crack initiation area was found to depend on the injection configuration.

The aim of the present study was to evaluate the ability to capture the effect on fatigue lifetime of the gradient of fiber orientation due to the injection flow around singularities. To specifically address this issue, the framework was kept identical to a proven lifetime estimation method. It was applied to notched-samples exhibiting the same notch radius -and therefore the same macroscopic stress concentration effect- but two different fiber orientation gradients ahead of the notch tips, originating from either axial or lateral injection. This type of specimen is not included in any standard and it was designed to assess experimentally and simultaneously the effect of notches and fiber orientation. To achieve this, the same notched specimens can be injected thorough two different injection gates, thus achieving different fiber orientation distributions throughout the entire specimen and particularly at the notch location. The specimens and the experimental plan are reported in Bernasconi et al. [26]. In this paper, we focus on a subset of experimental data presented in [26], i.e. fatigue tests conducted on specimens with a $2 \mathrm{~mm}$ notch radius.

Following the presentation of materials and fatigue tests in section 2, the selected lifetime estimation method proposed by Klimkeit et al. [11] was overviewed in section 3. It allowed linking the injection process simulation to the fatigue life assessment using a fatigue criterion, through the computation of local fields in the part as a function of the fiber orientation at each point of the part. The relevance of this TPM has been previously discussed from a large multiaxial fatigue database for PBT-PET GF30 and PA66 GF35 in standard injection-molded samples submitted to various fatigue loadings (tension, torsion, combined tension-torsion, pure shear) at ambient temperature. A major interest of this approach was to take into account the local fiber orientation in the computation of local effective properties and therefore to be able to distinguish both macroscopic stress concentration and fiber disorientation effects. In that work performed at ambient temperature, like in the present paper, the polymer matrix was assumed to be elastic. The method was extended later to take into account the viscoelastic 
behavior of the matrix at high temperature [25]. In section 4, this TPM approach was applied to two series of notched injection-molded samples. The strategy of criterion identification and application method was investigated. Critical areas predicted from the approach were compared to the experimental observations. Results were discussed in a final section.

\section{Material and methods}

\subsection{Material}

The tested material was a PA6 GF30, i.e. a Polyamide 6 filled with $30 \%$ weight short glass fibers (diameter $10.5 \mu \mathrm{m}$; average length $220 \mu \mathrm{m}$ ).

Two series of flat notched samples have been injection-molded, with the same geometry as depicted in Figure 1 but two different locations of the injection gate, denominated "top" (T) and "side" (S) in the following. Samples were $150 \mathrm{~mm}$ long, $45 \mathrm{~mm}$ wide and $3.2 \mathrm{~mm}$ thick plates with two lateral $\mathrm{V}$-shape notches at the longitudinal mid-section of the specimen and a $30 \mathrm{~mm}$ wide ligament in between. The notch tip radius was $2 \mathrm{~mm}$ for both $\mathrm{T}$ and $\mathrm{S}$ series. One can refer to Bernasconi et al. [26] for more details about the injection process. All specimens were conditioned until reaching hygrothermal equilibrium with an atmosphere of $23^{\circ} \mathrm{C}$ and $50 \%$ relative humidity following the procedure described in EN ISO 1110:2019 standard (with a slight deviation from the conditions suggested by the standard, i.e. accelerated conditioning was carried out at $70^{\circ} \mathrm{C}$ and $70 \%$ r.h. instead of $62 \%$ r.h.). Accelerated conditioning in a cabinet lasted 6 days, followed by weight monitoring every 2 days of control specimens, interrupted at stabilization of the control specimens' weight. Although the homogeneity of the water uptake through the thickness was not measured, the adoption of the widely accepted, above-mentioned procedure, combined with the relatively long time between conditioning and testing (several months, during which specimens were kept in sealed bags) allow to assume that a homogeneous distribution of absorbed water was achieved.

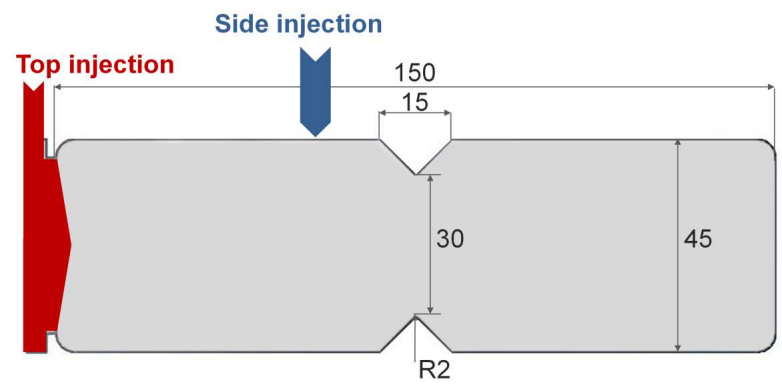

Figure 1: Geometry of the notched samples with indication of the injection gates for the Top and Side configurations.

\subsection{Fatigue tests}

Fatigue tests were performed at Politecnico di Milano using an Instron 8501 servo-hydraulic dynamic test system having a load capacity of $100 \mathrm{kN}$, as reported in [26]. The system is equipped with a calibrated load cell rated class 0.5 according to ISO $7500-1$ for loads greater than $1 \mathrm{kN}$, i.e. it has $0.5 \%$ accuracy of load measurements. Tests were conducted at a controlled room temperature of $23^{\circ} \mathrm{C}\left( \pm 2^{\circ} \mathrm{C}\right)$ in an air conditioned laboratory environment with uncontrolled humidity. Load-controlled tests were conducted with a sinusoidal wave signal, at a constant frequency of $4 \mathrm{~Hz}$ and a load ratio $\mathrm{R}$ (ratio of the minimum to the maximum applied load) of 0.1. Values of the maximum applied loads ranged from $3168 \mathrm{~N}$ to $5280 \mathrm{~N}$. The upper grip of the fatigue testing machine was fixed, while the load was applied by the lower moveable grip. The head of the specimen with the injection gate was clamped by 
the moveable lower grip. Specimens were clamped at their ends over a length of $35 \mathrm{~mm}$ using hydraulic grips with flat wedges. Lifetime $\mathrm{N}_{\mathrm{f}}$ was defined as the number of cycles at fracture of the sample into two separate parts. Crack growth was monitored in some specimens using the method of back lighting, which allowed to detect cracks thanks to the translucency of the material.

It is worth mentioning that although tests were conducted in a room with controlled temperature, the specimens may have undergone local temperature rise at notches due to selfheating induced by cyclic loading. The same self-heating may have led to progressive change of the water content. However, at first approximation it is reasonable to assume that the specimens of the $\mathrm{S}$ and $\mathrm{T}$ series have undergone the same phenomena for the same test duration and therefore that there is no influence of the aforementioned effects on the subsequent numerical analyses. Future work should investigate more in depth these aspects to improve the proposed modelling approach.

Fatigue test results are plotted in Figure 2, as the maximum nominal stress in the ligament $\sigma_{\max }$ (i.e. the maximum applied load divided by the initial cross-section area of the ligament) against the number-of-cycles-to-fracture, N. plotted in semi-logarithmic scale. The experimental scatter at a given load level was limited, as very often observed in injected samples of short-fiber reinforced thermoplastics. $\sigma_{\max }$ and $\mathrm{N}$ could be related by a Basquin law (Equation (1)).

$$
\sigma_{\max }=\sigma_{f} N^{m}
$$

where $\sigma_{f}$ and $m$ are two material parameters.

Figure 2 clearly demonstrates that the Top injection is a better configuration for fatigue resistance, with almost one decade more on the number-of-cycles-to-fracture. Exponent $m$ (0.95) was the same for the two injection configurations. The fatigue life was widely governed by crack initiation, which represented between $40 \%$ and $50 \%$ of the number-ofcycles-to-fracture for the two sample geometries [26].

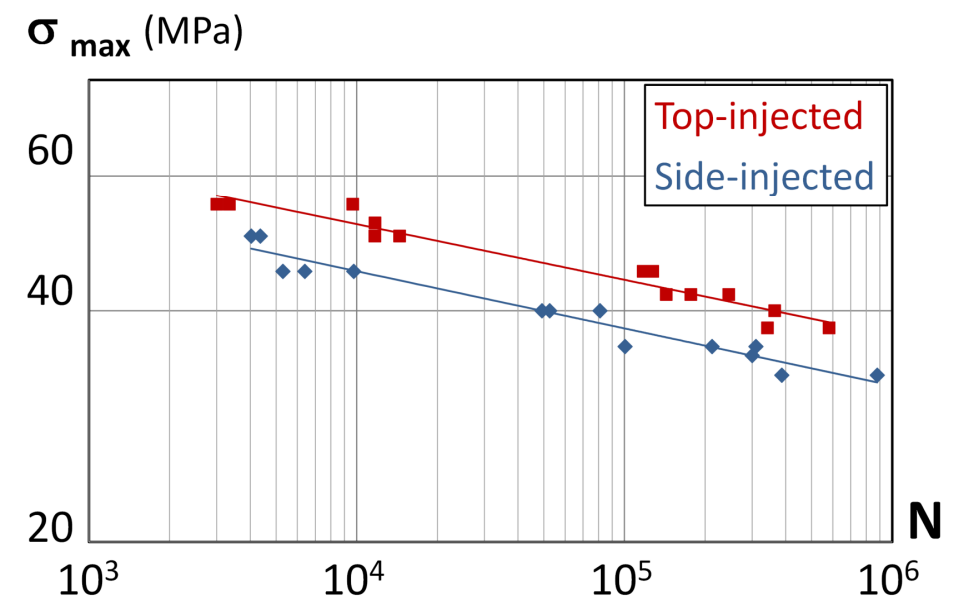

Figure 2: S-N curves at load ratio $\mathrm{R}=0.1$ for top-injected (square) and side-injected (circle) notched samples. 


\section{Overview of the Through-Process Modelling (TPM) method}

To account for the dependence of fatigue life on fiber orientation due to injection process, the selected approach (summarized in Figure 3) was the Through-Process Modelling (TPM) previously proposed by Klimkeit et al. [11] and validated in a PolyButylene Terephthalate / PolyEthylene Terephthalate reinforced with a mass content of $30 \%$ short glass fibers (PBT+PET GF30) over a wide range of multiaxial loadings.

The first step was the simulation of the injection process, with the aim to compute the orientation tensor of fibers at each point of the part. Moldflow ${ }^{\circledR}$ software was used here. Then, Digimat ${ }^{\circledR}$ software was used to link the injection simulation to the Finite Element analysis of the part (in the present case, conducted with Abaqus ${ }^{\circledR}$ software). Digimat ${ }^{\circledR}$ allowed two different tasks. The first one was to transfer the orientation tensor field from the Moldflow ${ }^{\circledR}$ mesh to the Abaqus ${ }^{\circledR}$ one. The second one was to compute by homogenization the local effective anisotropic properties at each point of the part. Within the elastic framework retained here, this was obtained from the matrix properties (Young's modulus and Poisson's ratio), the fiber properties (Young's modulus and Poisson's ratio too) and the composite morphology characteristics (fibers volume fraction, average length and average diameter). Values of these parameters are listed in Table 1.

A two-step homogenization procedure was followed. First, the stiffness tensor of unidirectional composites $\mathrm{C}^{\mathrm{UD}}$ (one single orientation of fibers) was calculated based on the Mori-Tanaka scheme. Then, the stiffness tensor of a misoriented composite was deduced by averaging $\mathrm{C}^{\mathrm{UD}}$ over the fiber orientation distribution, with an orthotropic closure approximation.

Once known the effective elastic properties at any point, the loading parameters and the boundary conditions, the elastic response of the part could be computed from Finite Element Method. Finally, mechanical fields depending on local fiber orientation were post-processed in order to get the equivalent mechanical quantity involved in the fatigue criterion, classically called Fatigue Indicator Parameter (FIP) in the literature.

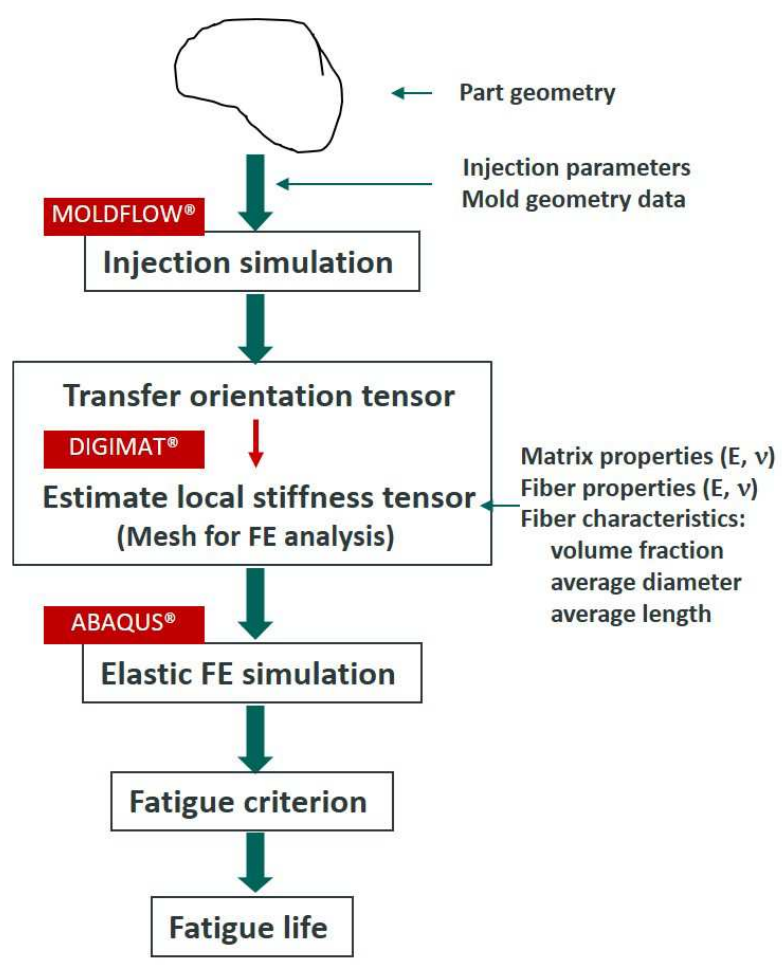

Figure 3: Overview of the Through Process Modelling (TPM) approach 


\begin{tabular}{|l|c|c|}
\cline { 2 - 3 } \multicolumn{1}{c|}{} & Glass fiber & Polyamide 6 \\
\hline Density $\left(\mathrm{kg} / \mathrm{m}^{3}\right)$ & 2540 & 1150 \\
\hline Young's Modulus $(\mathrm{MPa})$ & 72000 & 1200 \\
\hline Poisson ratio & 0.22 & 0.4 \\
\hline Weight ratio & 30 & \\
\hline Average diameter $(\mu \mathrm{m})$ & 10.5 & \multicolumn{1}{|}{} \\
\hline Average length $(\mu \mathrm{m})$ & 220 & \\
\hline
\end{tabular}

Table 1: Mechanical and morphological parameters used for modeling the PA6GF30 microstructure

The type of fatigue criterion and consequently the FIP, as well as the way of applying the criterion (e.g. volume average over each element of the FIP or more local approach) are distinct issues from the TPM method itself. Both can be customized within the TPM framework. The priority of the present work was not to refine the fatigue criterion and/or the application method but to test existing methods, in samples exhibiting the same macroscopic singularity but very distinct local fiber orientation.

Among simple fatigue criteria that may be identified by using a single S-N curve, Klimkeit et al. [11] showed that the energetic criterion due to Kujawski and Ellyin [27] provided good results over a rather wide range of un-notched sample geometries and multiaxial loadings. This criterion was retained here. It obeys Equation (2).

$$
f \Delta W=\kappa N^{\alpha}
$$

where $\Delta W$ is the strain energy density (Equation (3)) supposed to be elastic in the high-cycle regime, $f$ an empirical factor accounting for the mean stress effect and $\kappa$ and $\alpha$ are two material parameters. $f$ is obtained by solving Equation (4) where $\sigma_{m}$ and $\sigma_{a}$ are respectively the mean and amplitude stresses characterizing the macroscopic fatigue loading [27]. In the present case, $f$ was constant (equal to 1.78), due to the fact that all tests were performed at constant macroscopic stress ratio, $\mathrm{R}=0.1$. Thus, the FIP in the following will correspond to the elastic energy density (Equation (3)).

$$
\begin{gathered}
\Delta W=\frac{1}{2} \bar{\sigma}:= \\
f^{2}-\frac{\sigma_{m}}{\sigma_{a}} f-1=0
\end{gathered}
$$

Two application methods of this criterion were tested in the present work. They are explained in Section 4.2.

\section{Application of the TPM method to notched samples}

The TPM method was applied here to the T and S samples. Specificities of each step are depicted below.

\subsection{Fiber orientation}

Fiber orientation in the specimens studied in this paper was analyzed experimentally and results were reported in a previous paper [26]. Experimental results were available only at the 
specimens' gauge sections, whereas, to apply the TPM, the components of the fiber orientation tensor were needed over the entire specimens' volume. Therefore, injection process simulations were conducted with Moldflow ${ }^{\circledR}$ software using shell elements divided into 20 layers. The injection time was $1 \mathrm{~s}$, the packing pressure $45 \mathrm{MPa}$, packing time $6 \mathrm{~s}$, cooling time $16 \mathrm{~s}$, die temperature $90^{\circ} \mathrm{C}$ and molten material temperature $275^{\circ} \mathrm{C}$.

To evaluate the fiber orientation, the Reduced Strain Closure algorithm was applied, because in [28] it was proved to be able to describe more accurately the variation of the fiber orientation through the thickness of the same specimens as studied in this paper, in agreement with measured values. In [26] and [28], fiber orientation was measured applying the optical method described in [29], which infers the fiber orientation of each fiber by the eccentricity and orientation of the elliptical footprint left by the fiber over a polished physical section of the sample.

Values of the parameters $\mathrm{k}$, scalar factor, and $\mathrm{C}_{\mathrm{i}}$, fiber interaction coefficient, required by the RSC algorithm were calibrated through the comparison between numerical and experimental values of the components of the fiber orientation tensor through the width of the gauge section of both specimens. Optimum values of $\mathrm{k}$ and $\mathrm{Ci}$ were 0.4 and 0.01 , respectively. To compare numerical with experimental values at each point through the width, values of the fiber orientation tensor components were averaged through the thickness (a good through the thickness agreement was achieved in [28]). Nevertheless, it has to be pointed out that the fiber orientation is not homogeneous through both the thickness and the width. In any case, measurements and simulations confirmed that the fiber orientation in the gauge section of the $\mathrm{T}$ specimens is different from that of the $\mathrm{S}$ specimens, being that of the $\mathrm{T}$ specimens symmetric, whereas that of $\mathrm{S}$ ones is not.

Simulations provided the second-order orientation tensor of fibers, for each element of the part and each layer through the thickness. Figure 4 and Figure 5 display the longitudinal component $\mathrm{a}_{\mathrm{xx}}$ of this tensor in the fifth layer (within the skin) and the eleventh layer (within the core) of $\mathrm{T}$ and $\mathrm{S}$ samples. Figure 4 shows the full sample with an absolute scale ranging from 0 to 1, whereas Figure 5 focuses on the ligament area with adapted scales.

A first global observation is that samples do not exhibit any homogeneous fiber orientation within a given layer, neither in the skin nor in the core, not only in the gauge section, but also in large neighboring volumes. Therefore, samples cannot be assimilated to laminate materials, like sometimes done for flat samples cut out of flat injected plates, far from the gate and far from the edges.

A skin-core trend could be detected in the sample heads. In the heads of T samples, fibers looked mostly oriented in the longitudinal direction in the skin layer and close to the transverse direction in the core layer. However, the orientation was not as clearly parallel (skin layer) or perpendicular (core layer) to the injection direction as it is usually in flat injected plates. Orientation was opposite in the upper and lower heads of S samples, due to the difference of flow direction, but consistent with the general case.

The skin-core effect was much less clear close to the ligament, due to notches and to multiple edge effects. Figure 5 shows that the local orientation was significantly different in $\mathrm{T}$ and $\mathrm{S}$ samples in the notch area, which is the critical zone for crack initiation and fatigue failure. More or less pronounced dissymmetry was observed between the left and right notch tips. Both the skin and core layers appeared dissymmetrical in the S sample, whereas only the core layer was affected in the T one. Fiber disorientation always appeared stronger at the right notch tip (i.e. opposite to the injection gate in $\mathrm{S}$ samples). 


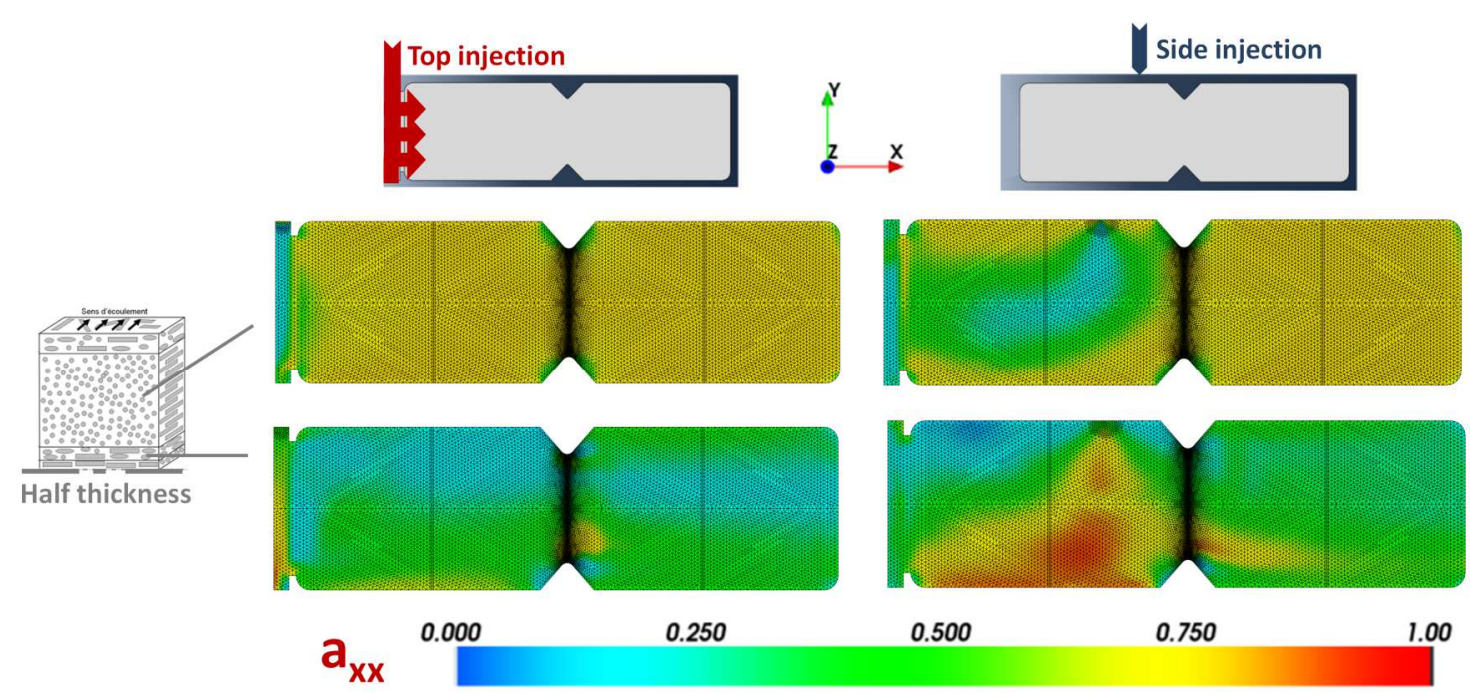

Figure 4: Map of the longitudinal (x) component of the second-order orientation tensor of fibers predicted from Moldflow® simulations in the skin (fifth layer on the top) and core (eleventh layer at the bottom) of top-injected (left) and side-injected (right) full samples (absolute scale from 0 to 1 in both cases).

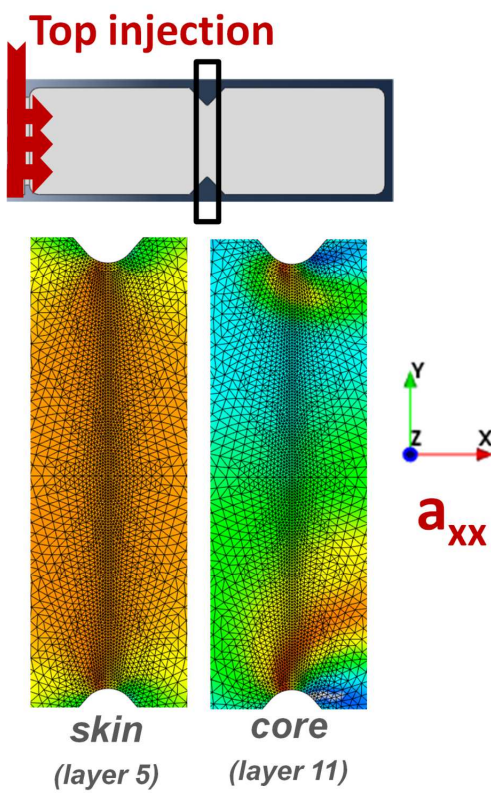

0.2

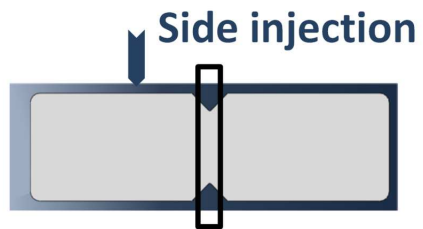

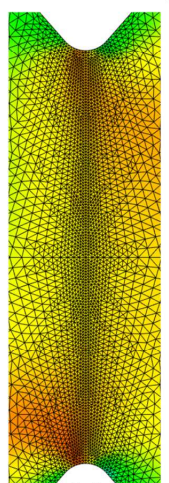

skin

(layer 5)

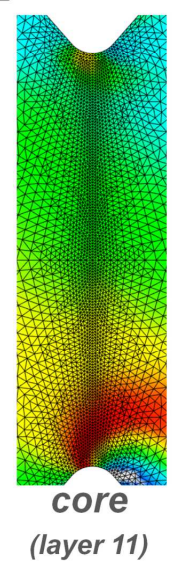

0.9

Figure 5: Zoom in the ligament area of the longitudinal (x) component of the second-order orientation tensor of fibers predicted from Moldflow ${ }^{\circledR}$ simulations in the skin and core of the ligament area in top-injected (left) and side-injected (right) samples.

\subsection{Finite Elements Analysis - Fatigue criterion application methods}

Finite Element calculations were performed with Abaqus®. Each sample was partitioned in order to generate a symmetrical mesh about the longitudinal axis and about the ligament. Then, the mesh was generated step by step using 2D triangular shell elements S3 with 20 layers in the thickness of the sample: the strip ahead of the notch tip was meshed first, followed by the fillet, the unclamped part of the heads and finally the clamped section of the heads. The average mesh size was $0.25 \mathrm{~mm}$ in the ligament area and $1 \mathrm{~mm}$ in the heads. Regarding the boundary conditions, samples were clamped over a $35 \mathrm{~mm}$ long part of the heads, as done in the experiments. All translation and rotation degrees of freedom were blocked in these clamped parts, except the longitudinal translation which was kept free in the 
section containing the gate, and clamped to the lower mobile grip for load application purpose. The same maximal load as experimentally applied was prescribed to the lower clamped head. One simulation was performed for each experimental load level and gave the mechanical fields from which the FIP (elastic energy density) was calculated at each integration point of the sample with Eq. (3). Even under uniaxial macroscopic loading which is the case here, local stress and strain tensors in Equation (3) are potentially multiaxial due to the local fiber orientation distribution and specimen geometry. In this way, several components of the stress and strain tensors were involved and not only the one in the loading direction.

Two different methods for the fatigue criterion application were studied in this paper. The socalled "average" method was proposed by Klimkeit et al. [11]. It consisted in averaging the simulated FIP over the volume of each element of the model and searching the maximum value over all the elements. This maximum value was then used as input for the criterion (Equation (2)). The so-called "hot spot" method was more local. It consisted in performing the arithmetic average of the FIP over the 3 integration points of each layer of each element, and searching the maximum value. This value was used as input for the criterion (Equation (2)). Python scrypts were developed for the post-processing of mechanical fields according to these two methodologies.

It is underlined that the application method was the same for both the criterion identification and the validation of the whole TPM.

\subsection{Identification of the fatigue criterion}

Material parameters $\kappa$ and $\alpha$ of the fatigue criterion (Equation (2)) were identified using only one S-N curve. Also, it is reminded that the mean stress correction factor was constant $(f$ $=1.78$ ). The identification methodology was as follows. The TPM was applied to the sample type corresponding to the chosen experimental S-N curve for every stress level of this curve. The resulting simulated values of $f \Delta W$ were plotted against the experimental number-ofcycles-to-fracture (in log-log scale). The interpolation equation directly provided the parameters $\kappa$ and $\alpha$ of the fatigue criterion.

Either the T or the S curve could be selected indifferently. Moreover, either the "average" or "hot spot" method could be used. Therefore, four identifications were conducted for comparison. Figure 6 illustrates these identifications, by plotting the simulated values of $f \Delta W$ as a function of the experimental number-of-cycles-to-fracture. Figure 6-a concerns the identifications based on the S-N curve of the Top-injected samples while Figure 6-b is related to identifications based on the S-N curve of the Side-injected samples.

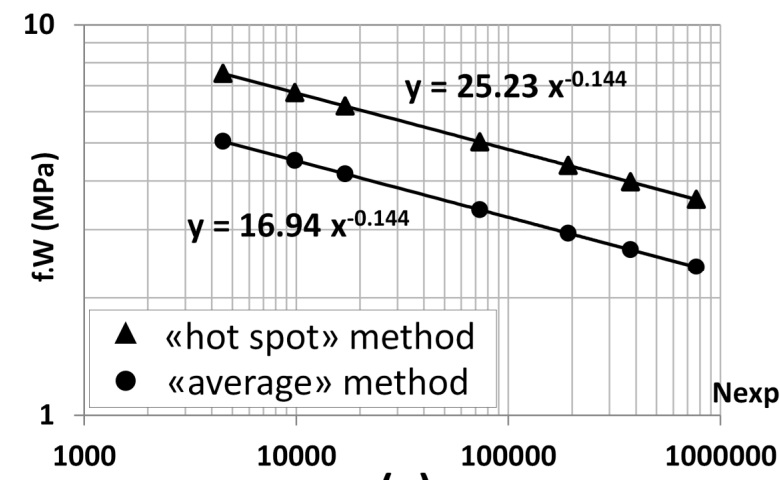

(a)

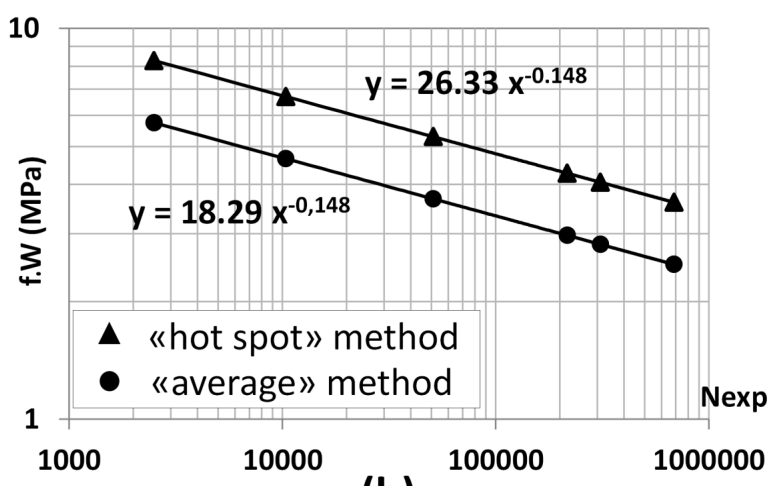

(b)

Figure 6: Illustration of the criterion identification based on the S-N curve of the (a) Top-injected samples and (b) Side-injected samples, with the "average" and "hot spot" methods in both cases. 
In each of the four cases, the very good alignment of points allowed to identify material parameters $\kappa$ and $\alpha$. The identified slopes were found to be identical for both the "average" and the "hot spot" application method, and only slightly different from each other when choosing the T or S series.

\subsection{Fatigue life prediction}

The TPM was applied to both types of samples ( $\mathrm{T}$ and $\mathrm{S}$ ) for each maximal load applied in the experiments. For each applied load level, the simulated number-of-cycles-to-fracture was calculated thanks to Equation (2) as follows:

$$
N_{\text {simulated }}=\exp \left(\frac{\ln (f \Delta W)-\ln (\kappa)}{\alpha}\right)
$$

where $f=1.78$ and $\Delta W$ was the maximum value over all the elements of the model when using the "average" method, or over all the layers when using the "hot spot" one. The parameters $\kappa$ and $\alpha$ were associated to the selected application method ("average" or "hot spot") and to the chosen S-N curve for the criterion identification (Section 4.3).

For each maximal load level applied in the experiments, Figure 7 compares the number-ofcycles-to-fracture experimentally measured and estimated from the TPM, using a fatigue criterion identified from the T series, either from the "average" method (Figure 7-a) or the "hot spot" one (Figure 7-b). The simulated and experimental S-N curves are expectedly overlapped in T samples, as a consequence of the fatigue criterion identification from this injection configuration. The quality of prediction should be appreciated from the $\mathrm{S}$ curves.

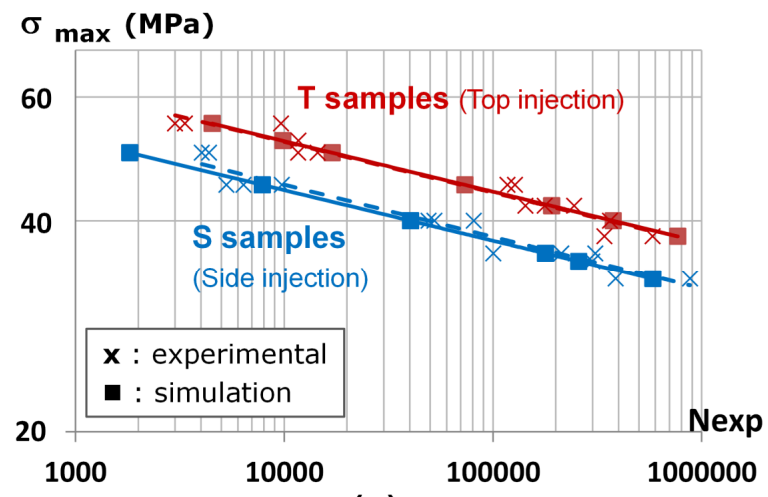

(a)

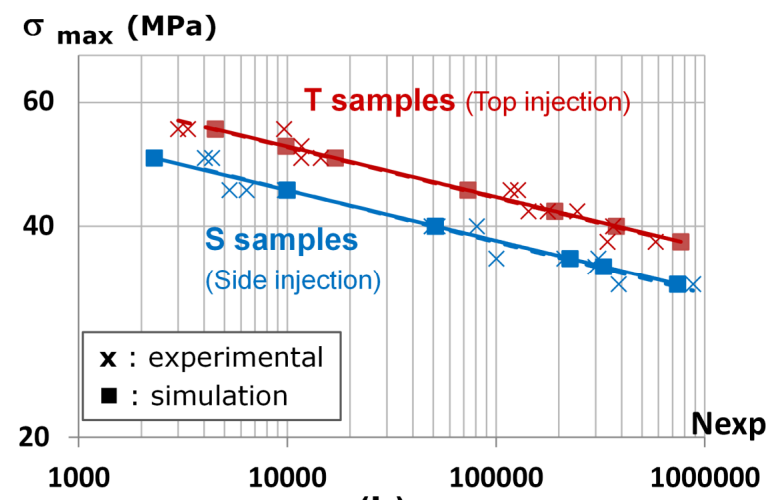

(b)

Figure 7: Comparison of S-N curves obtained from experiments (cross marks) and TPM simulations (square marks) with a fatigue criterion identified from the T series following the (a) "average" and (b) "hot spot" method.

Figure 8 displays the same type of results but after identification of the fatigue criterion from the $\mathrm{S}$ series. The quality of predictions must be discussed now from the T curves. 


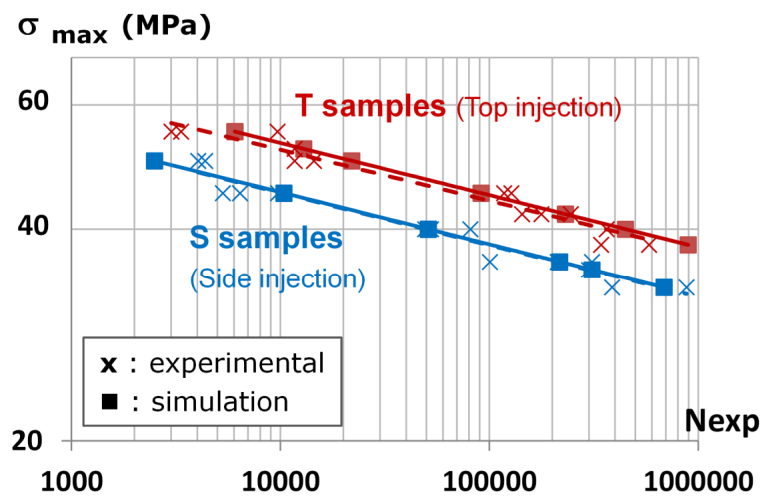

(a)

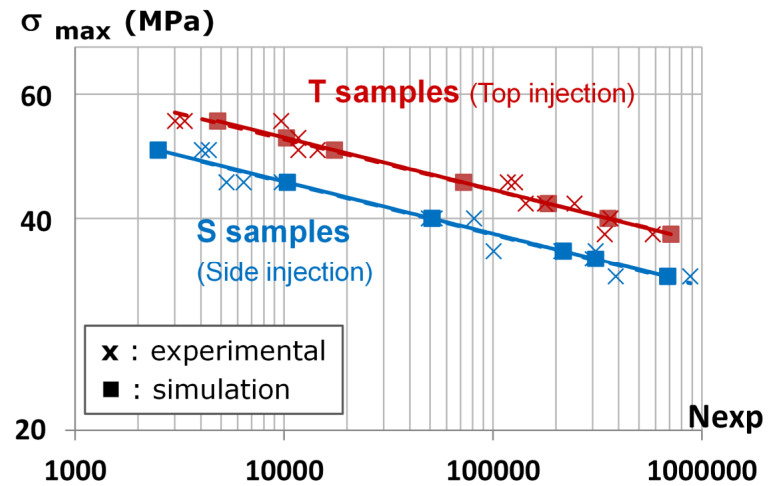

(b)

Figure 8: Comparison of S-N curves obtained from experiments (cross marks) and TPM simulations (square marks) with a fatigue criterion identified from the S series following the (a) "average" and (b) "hot spot" method.

Regarding the objective of the present work, the main result to be noted is the ability of the TPM approach to capture the microstructure effect (i.e. the heterogeneity of the fiber orientation) and consequently a strong difference between the fatigue lifetimes of samples elaborated from a significantly different injection configuration. This ability is supported by all graphs, regardless the S-N curve selected for the criterion identification and the application method. The microstructures being not homogeneous in the plane (whatever the location in the samples thickness) and this heterogeneity being moreover dependent on the injection configuration, a modelling approach assimilating the material as a laminate would not be able to capture the above mentioned difference between $\mathrm{S}$ and $\mathrm{T}$ samples.

For the same application method (average or hot spot), the comparison of Figure 7 and Figure 8 shows an equivalent quality of lifetime estimation when identifying the fatigue criterion from the Top or Side injected samples. It denotes the minor incidence of the injection configuration as a reference for the criterion identification.

The last point to be considered is the influence of the application method on the lifetime prediction. By comparing parts (a) ("average" method) and (b) ("hot spot" method) in Figure 7 and Figure 8, it seems that predictions were slightly better when identifying the criterion from a hot spot method. Nevertheless, the effect is minor.

\subsection{Fracture initiation detection}

The location of the critical point for fracture initiation could be deduced from the analysis and compared to the experiment. Figure 9 showcases the fatigue cracks in T (a) and S (b) specimens, after failure taking place after a number of cycles comprised between 350,000 and 400,000 . The cracks nucleated at a location slightly shifted from the notch root. In the experiments, two cracks originated from both notches. A key observation, which cannot be deduced from the post-mortem views in Figure 9, is that the main crack leading to the final fracture was observed to be initiated ahead of the bottom notch in the S samples, whereas two cracks were initiated and propagated simultaneously from both notches in the T samples [26]. 


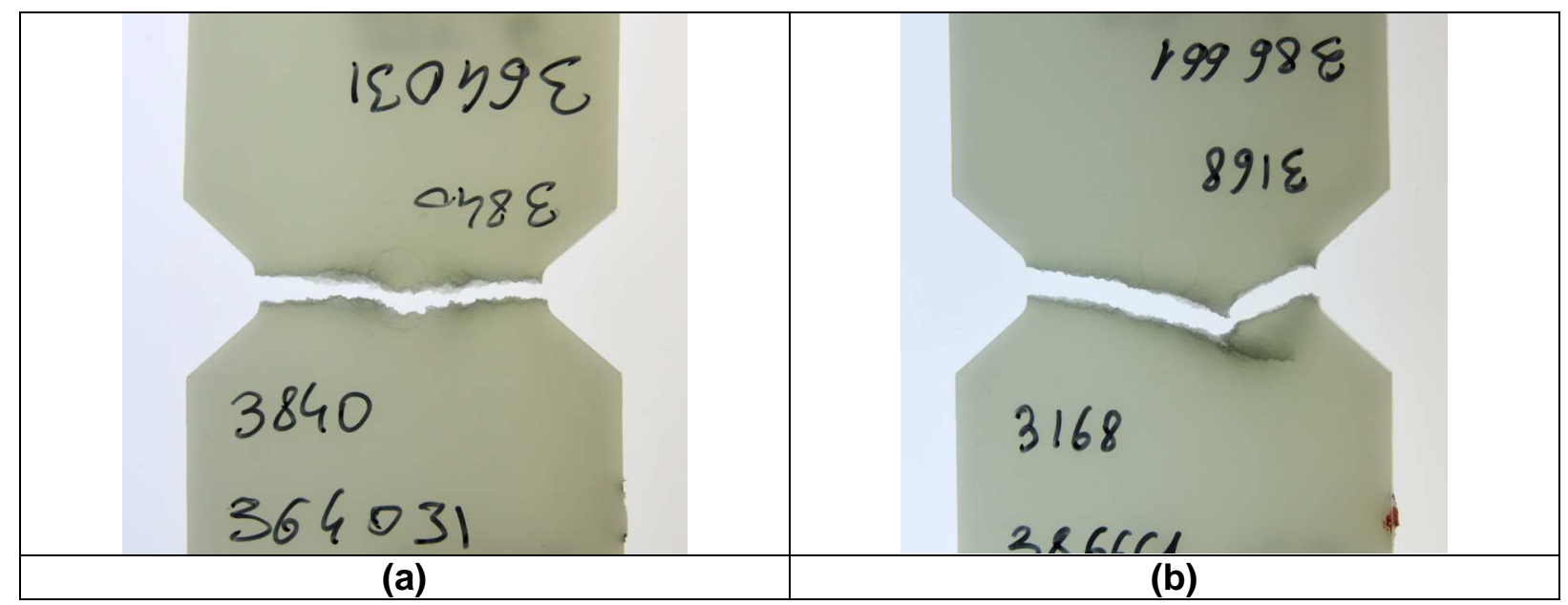

Figure 9: Fatigue cracks in $\mathrm{T}$ (a) and $\mathrm{S}(\mathrm{b})$ specimens

Figure 10 shows maps of the elastic energy in every notch tip area (i.e. around both notches for both the $\mathrm{T}$ and $\mathrm{S}$ injection configurations) for samples undergoing an applied maximum fatigue stress of $40 \mathrm{MPa}$. Maps are plotted with different scales for the top- and side-injected samples. The injection gate is located on the left for both sample types.

The critical points detected for fatigue lifetime estimation are indicated by white arrows. These critical points stand for both the "hot spot" and the "average" application methods of the fatigue criterion. Indeed, the layer with the maximal value of $\Delta W$ (detected for the "hot spot" application method) was contained within the thickness of the element with the maximal average value of $\Delta W$ (detected from the "average" application method).
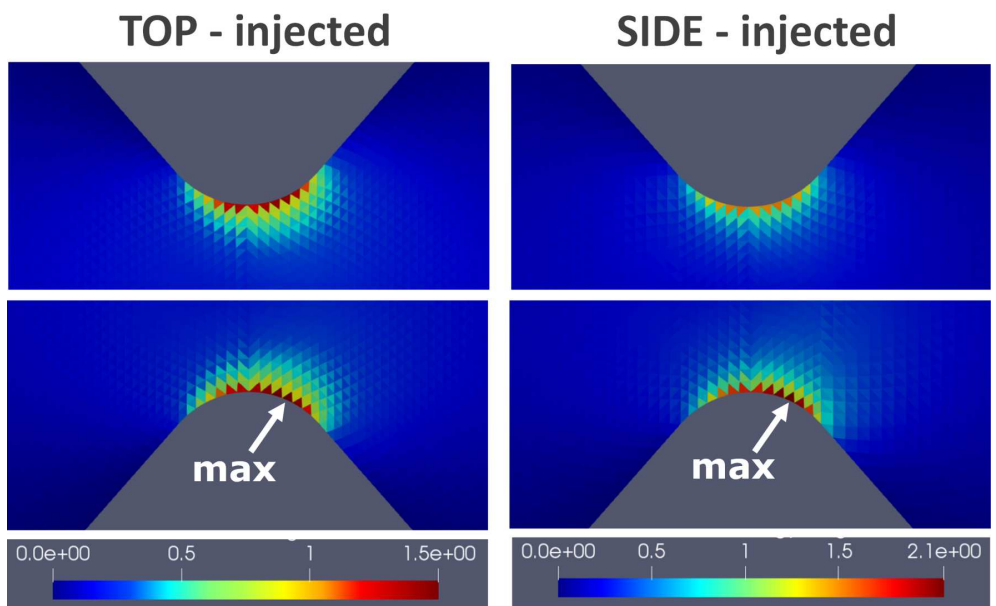

Figure 10: Maps of the simulated elastic energy (MPa) (average method) around both notches, in Top (left) and Side (right) injected samples undergoing a maximum fatigue stress of $40 \mathrm{MPa}$. Injection gate is on the left for all samples. White arrows indicate the location of the maximum value.

It is interesting to note that these points were detected close to the same notch tip but not exactly at the notch root, i.e. where they would have been located in a perfectly homogeneous material (i.e. without any variation of the material properties from one point to another). They were slightly shifted to the right of the notch root, i.e. towards the opposite side to the injection gate.

A possible effect of the fiber orientation was questioned and discussed from the magnified views of the orientation maps around notches displayed in Figure 11. As previously pointed out in Section 4.1, these orientation fields were not symmetrical either to the minimum area cross-section or to the injection axis. In both cases, the critical point depicted in Figure 10 
corresponded to rather disoriented fiber areas compared to zones at the notch root. Such effect was observed in both $\mathrm{T}$ and $\mathrm{S}$ samples. In the critical element of T-samples, the orientation tensor component along the longitudinal axis $\mathrm{x}\left(\mathrm{a}_{\mathrm{xx}}\right)$ was 0.51 and 0.26 , in the skin and core layer respectively. In the critical element of S-samples, the orientation tensor component along the longitudinal axis $\mathrm{x}$ was 0.5 and 0.3 , in the skin and core layer respectively. Symmetrically of the critical point to the ligament axis (i.e. on the injection side), fibers were significantly oriented in the tensile direction (i.e. $\mathrm{x}$ direction), for both $\mathrm{T}$ and $\mathrm{S}$ samples and both in the core and skin layers. Values of $\mathrm{a}_{\mathrm{xx}}$ respectively equaled 0.7 and 0.81 in the skin and core layer of $\mathrm{T}$ samples, and 0.8 and 0.87 in S samples.

Let us consider now the differences of orientation tensors close to the bottom and up notches. As visible in Figure 11, the orientation fields were only slightly different from each other in the $\mathrm{T}$ samples, whereas they significantly differed in the $\mathrm{S}$ ones. In the critical element itself, fibers in the skin were only slightly less aligned than in the skin of the symmetrical element in the top notch area. $\mathrm{a}_{\mathrm{xx}}$ value was 0.5 in the bottom notch, against 0.54 in the top notch. But all over a larger area around notches, fibers were much more aligned around the bottom notch than around the top one.

Figure 10 shows that the averaged energy displayed a consistent dissymmetry. Under a maximum applied stress of $40 \mathrm{MPa}$, the maximum value in the top notch area is only $5.7 \%$ less than in the bottom notch in T samples, whereas the difference is $27 \%$ in the S-sample. The slight difference of the energy values between the two notches in the T samples was consistent with the double crack experimentally observed in T samples. The stronger difference measured in $\mathrm{S}$ samples was consistent with the crack initiation experimentally observed in the bottom notch area only.

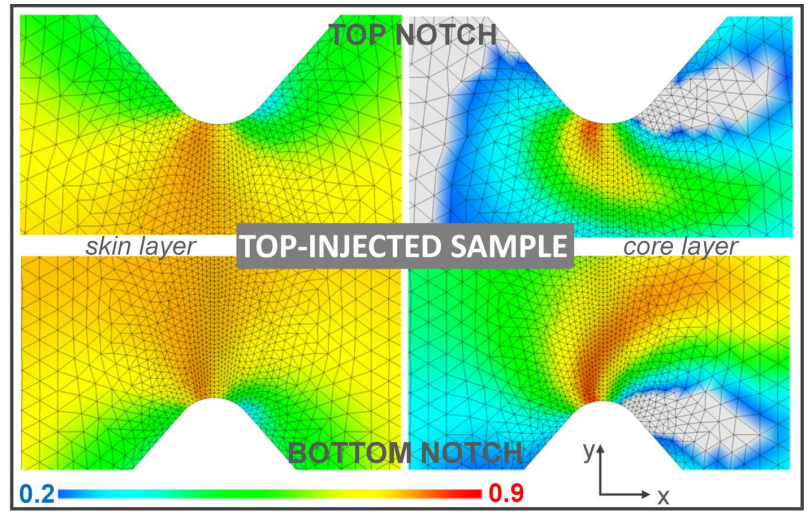

(a)

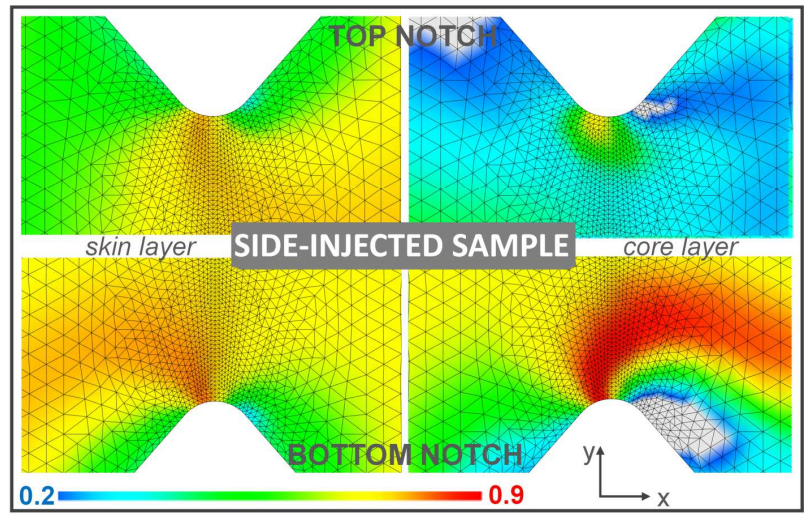

(b)

Figure 11: Map of the longitudinal (x) component of the orientation tensor of fibers ahead of the top and bottom notch tips in the (a) top-injected (T) and (b) side-injected (S) samples. Core and skin layers are mapped on the left and right sides respectively. 


\section{Discussion}

The current framework of the TPM approach was shown to be able to capture the microstructure effect in samples exhibiting macroscopic singularity but different orientation fields of fibers issued from two different locations of the injection gate.

As any fatigue design method based on crack initiation, the TPM approach is devoted to the high-cycle regime. In the present database, only a few number of experimental values were available at long lifetimes, compared to short ones. Nevertheless, predictions were logically better in the former range.

The proposed approach had limitations that can be discussed on several points.

Firstly, since the fiber orientation is known to be a first-order factor for the fatigue lifetime, the accuracy of any prediction method highly depends on the quality of the fiber orientation evaluation. The present work is no exception but the incidence was limited because all the compared methods used the same fiber orientation predictions as inputs. The interesting fact here was that the parameters of the injection simulation were previously optimized by comparing numerical predictions to experimental observations as detailed in Section 4.1. The second comment deals with the mesh size which directly affects the stress and strain values around a singularity like the notch tip. The mesh size was kept identical here for both the $\mathrm{T}$ and $\mathrm{S}$ samples. Independently on the microstructure effect that was mainly addressed here, the mesh size around the notch tips could be optimized, in order to improve the mechanical fields and the related lifetime predictions. However, a strong refinement of the mesh would be limited due to other consideration: indeed, the mesh size could not be refined more than the average fiber length, in order to keep the physical meaning of a Representative Volume Element underlying the homogenization process used to estimate the local effective properties within the sample as a function of fiber orientation. .

Thirdly, in the present work, the criterion application methods were very local ones. The way of applying the fatigue criterion in the case of high stress and/or strain gradients -and more precisely that of computing the FIP involved in the fatigue criterion- could be discussed. Although rather localized, it is interesting to notice in Figure 10 that the spatial extent of energy gradients was different for $\mathrm{T}$ and $\mathrm{S}$ samples, and also between the up and bottom notches. In the same way as already proposed for other materials, the FIP could be averaged over a larger volume around the critical point. May be such improvement could better capture differences between the fracture initiation location in T samples. Such a definition and optimization work of the integration volume should be processed along with the formulation of the criterion itself.

At the present temperature and relative humidity content, and even more at higher ones, the viscoelasticity of the matrix is expected to be non-negligible. It was not taken into account here, the purpose of the work being to capture the fiber orientation due to injection around singularities by the existing method. The choice to identify and validate the approach from notched samples minimized the impact of the constitutive law simplification.

The main interest of the present TPM approach is to allow addressing each step separately. Work is in progress on these issues, especially on the two last items. Indeed, the definition of an integration volume for the criterion application directly interacts with the notion of mechanical gradient around the singularity; and viscoelasticity directly affects those gradients. 


\section{Conclusion}

The present lifetime estimation method was based on a Through-Process Modeling already validated in several Short-Fiber Reinforced Thermoplastics, in flat samples or tubes exhibiting a skin-core microstructure with rather homogeneous fiber orientations by layers. The present work demonstrated the ability of this lifetime estimation method due to Klimkeit [11] to capture the conjugated effects of fiber orientation and macroscopic stress concentration in notched samples with the same geometry but elaborated from two different locations of the injection gate (Top-injection and Side-injection) and subsequently two different fields of the orientation tensor.

Two application methods of the criterion were compared. The FIP was either averaged over the volume of each element or picked up more locally from each layer of each element. The latter method provided very slight better lifetime estimation.

The identification of the fatigue criterion was based on the employment of a single experimental S-N curve. The incidence of the choice of the S-N curve on the quality of the lifetime prediction was investigated too and found to be negligible.

The predicted location of fracture initiation was consistent with experimental observations in Top-injected and Side-injected samples. It could be discussed from the orientation tensor maps and elastic energy fields. However, the question could be highly correlated to the application method of the fatigue criterion. It was very local in the present paper but work is in progress on the way how to define an optimized volume around the critical point over which the average should be performed. .

\section{Acknowledgements}

Computations have been performed on the supercomputer facilities of the Mesocentre de calcul SPIN Poitou-Charentes, partly funded by CPER-FEDER.

\section{REFERENCES}

1. Sato N, Kurauchi T, Sato S, et al., Microfailure behaviour of randomly dispersed short fibre reinforced thermoplastic composites obtained by direct SEM observation. Journal of Materials Science 1991; 26: 3891-3898.

2. Horst JJ. 1997, Fatigue fracture mechanisms and fractography of short-glass fibrereinforced polyamide 6. Journal of Materials Science 1997; 32: 3641-3651.

3. Bernasconi A, Davoli P, Basile A, et al. Effect of fibre orientation on the fatigue behaviour of a short glass fibre reinforced polyamide-6. International Journal of Fatigue 2007; 29: 199-208.

4. Klimkeit B, Castagnet S, Nadot Y, et al. Fatigue damage mechanisms in short fiber reinforced PBT+PET GF30. Materials Science \& Engineering A 2011; 528: 1577-1588.

5. Cosmi F, Bernasconi A. Micro-CT investigation on fatigue damage evolution in short fibre reinforced polymers. Composites Science and Technology 2013; 79:70-76.

6. Arif MF, Meraghni F, Chemisky Y et al. In situ damage mechanisms investigation of PA66/GF30 composite: Effect of relative humidity", Composites Part B Engineering 2014; 58:487-495.

7. Benaarbia A, Chrysochoos A, Robert G. Thermomechanical behavior of PA6.6 composites subjected to low cycle fatigue. Composites Part B: Engineering, 2015; 76: 52-64.

8. Rolland H, Saintier N, Wilson P et al. In situ X-ray tomography investigation on damage mechanisms in short glass fibre reinforced thermoplastics: Effects of fibre orientation and relative humidity", Composites Part B Engineering 2017; 109:170-186. 
9. Sonsino CM, Moosbrugger E. Fatigue design of highly loaded short-glass-fibre reinforced polyamide parts in engine compartments, International Journal of Fatigue 2008; 30: 1279-1288.

10. De Monte M, Moosbrugger E, Jaschek K et al. Multiaxial fatigue of a short glass fibre reinforced polyamide 6.6 - Fatigue and fracture behavior. International Journal of Fatigue, 2010; 32: 17-28.

11. Klimkeit B, Nadot Y, Castagnet $S$ et al. Multiaxial fatigue life assessment for reinforced polymers. International Journal of Fatigue 2011; 33: 766-780.

12. Launay A, Maitournam MH, Marco Y et al. Multiaxial fatigue models for short glass fibre reinforced polyamide. Part II: Fatigue life estimation. International Journal of Fatigue 2013; 47: 390-406.

13. Wilmes A, Hornberger K. Influence of Fiber Orientation and Multiaxiality on the Fatigue Strength of Unnotched Specimens - Lifetime Estimation. Procedia Engineering 2015; 133: 148-160.

14. Mortazavian S, Fatemi A. Fatigue behavior and modeling of short fiber reinforced polymer composites including anisotropy and temperature effects. International Journal of Fatigue 2015; 77: 12-27.

15. Raphael I., Saintier N., Rolland H., Robert G., Laiarinandrasana L., A mixed strain rate and energy based fatigue criterion for short fiber reinforced thermoplastics, International Journal of Fatigue 2019, 127: 131-143.

16. Santharam P., Marco Y., Le Saux V., Le Saux M., Robert G., Raoult I., Guévenoux C., Taveau D., Charrier P., Fatigue criteria for short fiber-reinforced thermoplastic validated over various fiber orientations, load ratios and environmental conditions, International Journal of Fatigue 2020; 135: art. 105574.

17. Zago A, Springer GS. Fatigue Lives of Short Fiber Reinforced Thermoplastics Parts. Journal of Reinforced Plastics and Composites. 2001; 20: 606-620.

18. Lazzarin P, Sonsino CM, Zambardi R. A notch stress intensity approach to assess the multiaxial fatigue strength of welded tube-to-flange joints subjected to combined loadings. Fatigue and Fracture of Engineering Materials and Structures 2004; 27: 127-140.

19. Zhou Y, Mallick PK. Fatigue Performance of an Injection-Molded Short E-Glass FiberReinforced Polyamide 6,6. I. Effects of Orientation, Holes, and Weld Line. Polymer Composites 2006; 27: 230-237.

20. De Monte M, Quaresimin M, Lazzarin P. Modelling of fatigue strength data for a short fibre reinforced polyamide 6.6 based on local strain energy density. In: Proceedings of the 16th International Conference on Composite Materials. Kyoto, Japan, 8-14 July 2007.

21. Bernasconi A, Cosmi F, Zappa E. Combined Effect of Notches and Fibre Orientation on Fatigue Behaviour of Short Fibre Reinforced Polyamide: Fatigue of SFRP: Notches and Fibre Orientation. Strain 2010; 46: 435-445.

22. Schaaf A, De Monte M, Moosbrugger E, et al. Life estimation methodology for short fiber reinforced polymers under thermo-mechanical loading in automotive applications. Materials Science and Engineering Technology, Special issue Structural Durability. Materials Science and Engineering Technology, Special issue Structural Durability Materialwissenschaft und Werkstofftechnik, 2015, 46: 214-228.

23. Quagliato L, Kima Y, Fonseca JH, Hana D, Yun S, Lee H, Park N, Lee H, Kima N, The influence of fiber orientation and geometry-induced strain concentration on the fatigue life of short carbon fibers reinforced polyamide-6, Materials and Design, 2020, 108569.

24. Serrano L. Caractérisation thermomécanique du comportement en fatigue des thermoplastiques renforcés de fibres de verre courtes. PhD Thesis, Université de Bretagne occidentale, France, 2015.

25. Fouchier N., Nadot-Martin C., Conrado E., Bernasconi A., Castagnet S., Fatigue life assessment of a Short Fibre Reinforced Thermoplastic at high temperature using a Through Process Modelling in a viscoelastic framework, International Journal of Fatigue, 2019; 124: 236-244.

26. Bernasconi A, Conrado E, Hine P. An experimental investigation of the combined influence of notch size and fibre orientation on the fatigue strength of a short glass fibre reinforced polyamide 6. Polymer Testing 2015; 47: 12-21. 
27. Kujawski D, Ellyin F. A unified approach to mean stress effect on fatigue threshold conditions. International Journal of Fatigue 1995; 17: 101-106.

28. Caton-Rose P, Hine P, Bernasconi A et al. Experimental and numerical analysis of fibre orientation in injection moulded short glass fibre reinforced Polyamide 6 notched specimens, in Proceedings of the $16^{\text {th }}$ European Conference on Composite Materials, Seville, Spain, 22-26 June 2014.

29. Hine PJ, Davidson N, Duckett RA et al. Measuring the fibre orientation and modelling the elastic properties of injection-moulded long-glass-fibre-reinforced nylon. Composites Science and Technology 1995; 53: 125-131. 